\title{
La teoría de la acción social en Erving Goffman
}

\author{
Manuel Herrera Gómez \\ Rosa María Soriano Miras \\ Universidad de Granada. Departamento de Sociología \\ mherrera@urg.es \\ rsoriano@ugr.es
}

\section{Resumen}

El presente artículo ofrece una reflexión sobre una figura clave en sociología como es Goffman. Proponemos un viaje a través de su obra con el fin de profundizar en su modelo dramatúrgico. Acción ubicada, presentación del self, frames o interacción social, son elementos abordados a través de la comparativa con otros autores, entre los que se encuentran Parsons, Durkheim e incluso el propio Freud. La obra de Goffman se ha analizado desde múltiples perspectivas, dando lugar a diversas interpretaciones, pero sin lugar a dudas lo que emerge de ella es una continua pretensión de dibujar el difícil y complejo encuentro entre lo micro y lo macro, sin poder encasillarse en ninguna corriente teórica conocida.

Palabras clave: teoría sociológica, modelo dramatúrgico, interacción social, análisis estructural.

\section{Abstract. The theory of social action by Erving Goffman}

This article is a reflection on an outstanding figure in Sociology: Goffman. We suggest a view of its works in order to go deeply into its dramatist model. Located action, presentation of self, frame on social interaction are some of the elements we dead with though a comparative with other authors, such as Parsons, Durkheim and even Freud. Goffman's work has been analysed from numerous perspectives, offering several interpretations, but what remains still is, without any doubt, a constant aspiration of drawing the difficult and complex encounter between the micro and the macro, without being categorized in any of the well-knowm theoretical trends.

Key words: sociological theory, dramatist model, social interaction, structural analysis.

\section{Sumario}

\section{Introducción $\quad 6$. Acción social y lenguaje cotidiano}

2. La acción social como acción «ubicada»

7. Orden de la interacción y orden social

3. La acción social como «presentación

8. El actor: la fisonomía del «enlace» de sí mismo»

4. Rol y distancia «de rol» Bibliografía

5. Descodificación de la vida cotidiana: ¿variables estructurales of frames? 


\section{Introducción}

Los primeros estudiosos de Goffman han visto en él un brillante e «irregular» intérprete de la vida cotidiana. Sin embargo, esto no sería suficiente para ser un teórico social serio y riguroso. Con el paso del tiempo, ha ido ganando terreno una valoración diferente de su obra. Algunas monografías - como The Presentation of Self in Everyday Life o Asylums - son consideradas actualmente como «clásicos» de la sociología (Riggins, 1990; Lamo de Espinosa, 2001). Ciertos autores reconocidos estiman que Goffman está a la altura de un pensador sistemático (Giddens, 1988; Kendon, 1998) o, incluso, lo consideran como «el sociólogo más grande de la segunda mitad del siglo XX» (Collins, 1988: 41).

Sin embargo, Goffman muestra una singular ambivalencia en las confrontaciones de la investigación teórica (Burns, 1992). Por una parte, concentra su atención en la interacción cara a cara. Por otra, declara querer abrir «una de las perspectivas sociológicas mediante la que se puede estudiar la vida social» a través de la elaboración de «un esquema de referencia que pueda utilizarse en el análisis de todo sistema social, ya sea familiar, industrial o mercantil» (Goffman, 1959: 9).

Es difícil identificar a Goffman en alguna tradición sociológica. Sin embargo, lo más común ha sido considerarlo un «desviado». La obra de Goffman se presta, por su riqueza, a múltiples interpretaciones. Lo que sí es cierto es que en su pensamiento permanece una sustancial continuidad teórica y que él mismo señala de manera manifiesta como el descubrimiento y la recognición del «orden de la interacción» (Goffman, 1983). Y es que su análisis de la estructura y de los caracteres propios de la interacción cara a cara ha sido innovador y original (Dawe, 1973: 246).

\section{La acción social como acción «ubicada»}

A pesar de haberse desarrollado en diferentes etapas, la reflexión de Goffman muestra claramente una línea de continuidad. Ya el primer estudio monográfico, The Presentation of Self in Everyday Life, es presentado como un "manual» para analizar todas aquellas situaciones en las que los individuos se encuentran en inmediata presencia unos con otros influenciándose recíprocamente (1959: 9, 26). En numerosos ensayos posteriores, Goffman reivindica la centralidad de la «situación social», lamentándose, sin embargo, de que haya sido olvidada en el análisis lingüístico y sociológico (1964). En su último escrito, llegó a recordar: «Mi intento [...] ha sido que se acepte el ámbito de la presencia cara a cara como un campo de análisis, un ámbito que se puede llamar [...] el orden de la interacción, un ámbito cuyo mejor método de estudio es el microanálisis» (1983: 3). ¿Qué significa esto? Significa que si «el sustrato de un gesto (o de una acción social) consiste en el cuerpo de quien lo realiza, la forma del mismo gesto puede estar muy determinada por la proximidad de la órbita micro-ecológica en la que se encuentra el sujeto. Para describir el gesto y, con mayor razón, para descubrir el significado debemos introducir en el 
discurso el ambiente humano y material en el que el mismo gesto se realiza» (1964:134). Ya que el sujeto siempre actúa utilizando aquella parte del ambiente "que le es más próxima», Goffman considera necesario «encontrar una forma para tener en cuenta de manera sistemática este ambiente» (ibídem).

Utilizando la expresión "orden interactivo», Goffman ha querido reivindicar la autonomía del nivel de las relaciones cara a cara, pero también su constitución compleja y «ordenada». Sólo desde una mirada rápida y superficial la interacción social se presenta constituida de relaciones, acuerdos y compromisos frágiles, causales y extratemporales. En realidad, desde sus primeras obras, Goffman ha mostrado hasta qué punto este nivel de la vida social está estructurado, trastocando la tradicional ecuación: nivel macro = complejidad; nivel micro = simplicidad (Knorr-Cetina, 1981).

El mundo de las relaciones cara a cara también se rige por un sistema articulado y persistente de reglas, normas y rituales. El orden de la interacción se basa en dos tipos fundamentales de reglas: por una parte, las «convenciones habilitadoras»; por otra, las normas basadas en principios y valores que los individuos aceptan porque las consideran como intrínsecamente justas. Aceptar estos dos tipos de normas (el contrato social y el consenso social) produce una «efectiva cooperación» (1983: 12).

Es precisamente esta doble diferenciación normativa la que no advertimos al dar por descontada nuestra forma de actuar en las relaciones sociales y obviando la complejidad de dicho comportamiento. El esfuerzo de Goffman ha sido intentar correr el velo de las apariencias para arrojar una luz sobre las reglas y los mecanismos.

Es a la luz de este interés, y de esta decisión, central en su teoría desde donde emerge una primera, y fundamental, característica de la acción social para Goffman. El sentido social de nuestras acciones siempre debe comprenderse en relación con la situación interactiva en que surge (ibídem: 7).

La visión del orden de la interacción como una esfera de acción relativamente autónoma, que los individuos activamente construyen, ha llevado en más de una ocasión a considerar a Goffman como próximo a la perspectiva del interaccionismo simbólico; sin embargo, la caracterización de este orden en términos esencialmente normativos y de constreñimientos sociales también ha llevado a ver en Goffman un funcionalista. En realidad, Goffman toma las oportunas distancias de ambas posiciones. Juzga «superficiales» a las ciencias sociales, siendo muy clara la referencia al estructural-funcionalismo y al marxismo, que consideran el mundo de las relaciones sociales cara a cara como «una expresión de» estructuras sociales más amplias (ibídem: 15). La relación entre prácticas de interacción y estructuras sociales, al menos en las sociedades modernas, se presenta en Goffman de manera compleja y articulada (ibídem: 16). Sin embargo, Goffman también se distancia de los planteamientos microsociológicos — como el interaccionismo simbólico y la teoría del intercambio social de Homans-, que conciben las situaciones interactivas y el mismo orden general de la sociedad como el producto de la intencionalidad, de los intereses o de las motivaciones individuales, enfatizando la con- 
tingencia de la acción social de los individuos (Giglioli, 1990: 12-14). Es muy consciente de los «efectos durkheimianos» (Goffman, 1963: 14), es decir, de aquellos vínculos normativos (valores, normas, representaciones colectivas y formas de control social) que se imponen externamente, condicionándola, a la interacción de los individuos.

Ahora bien, aunque Goffman tienda a distinguirse tanto del funcionalismo como de las microsociologías constructivistas, su posición no es de equidistancia (Goffman, 1974: 13). Goffman se considera más próximo al estructural-funcionalismo, como Parsons o Merton, igual que ellos estaban más próximos a la primera antropología funcionalista.

La posición de Goffman se separa netamente de aquellos planteamientos que identifican el mundo de las relaciones cara a cara con las relaciones comunitarias. En su último escrito, expresa de manera tácita la necesidad de que la sociología se libere de la tradicional distinción entre relaciones primarias y secundarias (1983: 12). El orden interactivo se construye allí donde «dos o más personas están físicamente próximas la una de la otra», por lo que «las reglas del tráfico peatonal pueden ser estudiadas en cocinas y en calles repletas de gente, los derechos de interrupción tanto en el desayuno como en las salas de los tribunales, las caricias en los supermercados y en el dormitorio" (ibídem: 2-3). Las relaciones cara a cara pueden asumir indiferentemente la forma de las relaciones primarias o secundarias, formales o informales, simétricas o asimétricas, de Gemeinschaft o de Gesellschaft.

Por este motivo, la perspectiva de Goffman se distancia de aquellas teorías que atribuyen a las relaciones cara a cara una particular cualidad «humana». Es el caso de la teoría de la acción comunicativa de Habermas (1981) y su contraposición no sólo analítica, sino también axiológica y normativa, entre Lebenswelt y los sistemas sociales funcionales de la economía y de la política. Goffman evita estos sentimentalismos sociológicos.

\section{La acción social como "presentación de sí mismo»}

Si la primera característica de la acción social es su naturaleza esencialmente ubicada, la segunda es que siempre posee una dimensión comunicativa de "presentación de sí mismo» (Goffman, 1959; 1967).

En la introducción de Behavior in Public Places (1963), Goffman indica que cuando las personas están la una ante la otra "pueden funcionar no sólo como instrumentos físicos, sino también como instrumentos de comunicación", siendo las informaciones que los participantes emiten comunicaciones «incorporadas». Por ello, la primera regla situacional consiste en la "gestión disciplinada de la propia apariencia o fachada personal» (ibídem: 27).

En las diferentes situaciones de interacción todo individuo se presenta a sí mismo, a través de sus acciones, que por ello son siempre comunicativas. Dicha acción tiene como finalidad presentar un determinado perfil de persona caracterizada por ciertos atributos positivos. Su intención es que tal pretensión de «identidad» sea tomada seriamente y, con tal fin, busca gestionar y controlar 
lo más posible —mediante sus acciones y comportamientos— la «impresión» que los otros recaban de él. Por tanto, la acción social siempre es performance, representación para un público, y esto constituye un aspecto esencial de su «sentido» social. De forma detallada, Goffman describe el esfuerzo y las estrategias que activan los individuos para presentar una imagen «idealizada» de sí mismos, esto es, ventajosa para ellos y veraz para los otros. En esta perspectiva, el actor social, como tradicionalmente ha sido concebido por la sociología (como actor portador de roles), se convierte en un «actor» en el sentido propio de la metáfora dramatúrgica.

Sin embargo, el actor jamás es del todo consciente y «dueño» de la propia performance. Por eso distingue entre las comunicaciones que el actor trasmite intencionalmente y las expresiones que «deja entrever» (1959: 12-17). Las primeras son acciones dotadas de sentido desde el punto de vista del sujeto. Sin embargo, las segundas comprenden una amplia gama de acciones que los observadores pueden considerar sintomáticas del actor. Estas últimas acciones tratan todos aquellos aspectos del comportamiento no verbal más difíciles de controlar o disimular, a través de los cuales los interlocutores «pueden servirse como medio para verificar la verdad de cuanto es trasmitido por los aspectos controlables» (ibídem: 17). Por lo tanto, el individuo no sólo trata de acreditar una cierta imagen de sí; contextualmente, siempre proyecta una propia «definición de la situación» (ibídem: 19-23, 277-279). Ahora bien, en general prevalece una definición común (Goffman, 1963: 97-99).

Aunque Goffman se centre en el estudio de los «sistemas ubicados de actividad», subraya que, generalmente, la situación de interacción está ya predeterminada por la sociedad y, en tal sentido, precede y condiciona los espacios y las formas de acción de los individuos (De Biasi, 1995). Al tratar la presentación de sí mismo, Goffman había aclarado que la imagen que ofrece el individuo a los otros (su «fachada personal») no es una construcción arbitraria y extratemporal, sino un "equipamiento expresivo de tipo estandarizado».

La misma caracterización positiva de la fachada o del personaje - aquello que Goffman define como «idealización»- alude a aquellos atributos que consiguen consenso y aprobación al expresar valores y jerarquías socialmente aceptadas (y esto es válido, del mismo modo, incluso para las idealizaciones negativas, es decir, para aquellas representaciones sistemáticamente encaminadas a disminuir y reducir el efectivo estatus de la persona) (Goffman, 1959: 47-63). La misma habilidad para asumir de forma apropiada las diferentes fachadas, personajes y roles siempre es el resultado de un proceso de "fijación", de estabilización de la capacidad representativa, que constituye uno de los aspectos clave de la socialización (ibídem: 82-88).

Aunque en todas las situaciones de interacción exista (al menos operativamente) un cierto grado de consenso, siempre se presentan como relaciones de poder. Algunas situaciones - como en las cárceles - presentan una estructura interactiva más «determinista» que deja poco espacio a las estrategias negociadoras de los individuos (Goffman, 1961a), mientras que otras permiten mayores márgenes de acción y de performance. Sin embargo, incluso en las 
situaciones más rígidamente predefinidas tales definiciones siempre deben ser renegociadas dentro de un constante flujo de señales, acciones y reacciones que se dan en la concreta relación social (Danziger, 1976).

De lo dicho hasta ahora queda claro que tanto la «definición de la situación» como la "presentación de sí mismo» no constituyen dos procesos más o menos ligados, sino dos caras de un único proceso social. Esto permite ubicar con mayor precisión el análisis goffmaniano en el trasfondo de la teoría de la acción social, a través de tres cuestiones clave:

1. Goffman reformula el concepto weberiano de acción social dotada de sentido. Dicho en otros términos, para Goffman el sentido de la acción depende de las características de la situación interactiva y del contexto sociocultural en el que los individuos actúan. Por lo que respecta a las perspectivas interpretativas del actor y del observador, el sociólogo norteamericano señala que pueden divergir, en cuanto que el observador dispone de una doble clave de lectura. No sólo puede reconocer el sentido intencional atribuido por el actor, sino que también puede captar un segundo estrato de significados: aquellos aspectos y comportamientos sintomáticos, inconscientemente vislumbrados, que permiten integrar su interpretación de la acción del otro.

2. La interacción siempre implica un complejo juego de interpretación de la acción recíproca, que Parsons había sintetizado en el concepto de «doble contingencia» (1951: 11-74). Sin embargo, Goffman va más allá del mismo Parsons en la profundización sobre tal concepto, tal y como ha reconocido uno de sus más importantes discípulos, Alexander (1987).

3. Retomando los conceptos de Weber y Tönnies, Parsons ha diferenciado entre acción expresiva y acción instrumental (1951; con Shils, 1951). Para Goffman, toda acción ante un público es conjuntamente expresiva e instrumental.

\section{Rol y distancia «de rol»}

El objeto de la perspectiva dramatúrgica es la acción de un actor —o de un equipo de actores- que pretende representar un personaje o una singular rutina ante un público. Por tanto, el actor siempre se presenta ante el público (y ante la observación sociológica) con los «ropajes» de un particular personaje (Goffman, 1956: 482).

Este tema ha estado presente desde el principio en la reflexión de Goffman, y se desarrolla de forma sistemática en un estudio que, sin lugar a dudas, constituye una de las más importantes aportaciones sociológicas en el análisis de los roles sociales. En Role Distance (1961b), Goffman pretende «examinar críticamente los análisis referentes al rol social» (ibídem: 4) para construir una teoría más articulada y multidimensional (ibídem: 92). Debido a sus «implicaciones deterministas», no le satisface el tradicional análisis estructural-funcionalista. $\mathrm{Al}$ mismo tiempo, considera insuficientes las perspectivas que asu- 
men el punto de vista del individuo con la multiplicidad de sus sí mismos (de rol) (ibídem: 89).

En consecuencia, Role Distance no presenta, como sostienen algunos, una discontinuidad o una corrección de la perspectiva dramatúrgica, en el sentido de conferir mayor consistencia al actor social diluyendo el determinismo societario presente en las primeras obras. Parece más bien lo contrario, puesto que Goffman intenta "poner a prueba" los conceptos clave de su planteamiento dramatúrgico introduciéndose en un debate central para la sociología, la cuestión micro-macro.

Partiendo de la clásica distinción de Linton (1936), Goffman examina los desarrollos y las aproximaciones conceptuales elaborados en el ámbito estructural-funcionalista e interaccionista desde los años cincuenta: los conceptos de complejo de roles (roleset), sectores de rol (o subroles), funciones de rol (funcionales/disfuncionales, manifiestas/latentes), compromiso de rol, conflicto de rol y disenso de rol (interrol e intrarrol), roles ocultos, «jugar a un rol», etc. Intenta retomar y recontextualizar estos conceptos dentro de la «perspectiva situacional» que aparece en obras precedentes (ibídem: 3-10). Dicha tarea analiza la acción en el rol no en abstracto y en general, sino aludiendo al «sistema situado de actividades» en el que concretamente se realiza (ibídem: 95).

Para Goffman, una teoría correcta de la acción de rol debe distinguir tres niveles analíticos diferentes: $a$ ) el modelo normativo del rol; $b$ ) el rol típico, y c) la «prestación de rol» o «ejecución de rol» (ibídem: 83-92).

La perspectiva interaccionista se centra en el aspecto de la construcción y de la negociación de los roles en la interacción, ignorando, sin embargo, la dimensión normativa. Por su parte, la perspectiva estructural-funcionalista tiende a colapsar un nivel sobre otro, llegando a concebir la prestación concreta de rol como mera consecuencia y epifenómeno de las peticiones normativas del rol. Sin embargo, Goffman mantiene que la situación es mucho más compleja: «Si contemplamos el comportamiento del individuo momento por momento, descubrimos que no permanece pasivo ante la producción de potenciales significados que lo controlan, sino que cuando lo logra, participa activamente en sostener una definición de la situación que sea estable o coherente con la imagen que tiene de sí mismo» (ibídem: 104). Entonces, el rol que el individuo juega en un específico contexto de interacción siempre será «algo más que aquello que se reduce a simples hechos causales o incidentes, y algo diferente de lo que se puede reducir a la pertenencia a una institución en cuanto tal y de la ubicación en su jerarquía y en sus tareas formales» (ibídem: 95-96).

Los motivos de insatisfacción de Goffman en las confrontaciones del determinismo insertado en las teorías estructural-funcionalistas se concentran en dos aspectos. En primer lugar, estas teorías toman en consideración los roles estructurales en instituciones, definidos en términos de expectativas y sanciones. En segundo lugar, la perspectiva estructural-funcionalista tiende a ser "aséptica», en el sentido de que separa de forma artificial el comportamiento requerido en un determinado rol del conjunto de otras actividades. En todo rol situado, particular, sin embargo existe un «halo de par- 
ticipación» constituido por la pluralidad de selves del individuo que influencian, interactúan, crean ecos y repercusiones en la concreta ejecución de rol (Goffman, 1961b: 96).

De esta forma, Goffman desarrolla un complejo análisis centrado en dos conceptos opuestos, pero complementarios: asunción de rol y distancia de rol. A través de ellos, se capta una continuidad con los temas originarios en la representación, como la sinceridad y el cinismo. Para ilustrar estos conceptos, Goffman parte de dos situaciones diferentes entre sí. Por una parte, la actividad lúdica de los niños de edades diferentes sobre el juego; por otra, el serio trabajo de un equipo de cirugía, en el que se requiere eficiencia y profesionalidad. El objetivo es hacer emerger el aspecto «situacional» (común) de los aspectos «meramente situados» (contingentes).

«Asumir un rol - explica Goffman - significa desaparecer completamente en el sí mismo virtual elaborado por la situación, exponerse a la percepción de otros mediante la propia imagen y confirmar expresivamente la propia aceptación de ella. Asumir un rol significa ser subsumido por éste» (ibídem: 106). La asunción implica adhesión "con el corazón y con la cabeza» y la explícita voluntad «de abandonarse en el rol y aprovechar las ventajas en términos de identidad de lo que puede dar» (ibídem: 87-88). Éstas son las dos primeras condiciones de la asunción del rol. Sin embargo, debe estar presente una tercera condición: la posesión de los requisitos y las habilidades necesarias para ejecutarlo (ibídem: 106). La verificación de una de las condiciones no implica necesariamente la presencia de las otras. De esta forma, la adhesión al rol no significa por sí mismo la capacidad de ejecutarlo de manera competente.

Al mismo tiempo, ostentar una elevada asunción del rol puede esconder una ausencia real de adhesión (como ocurre con el «ritualista» de Merton (1968). Por este motivo, Goffman señala que existen profesiones que facilitan la identificación con el rol, concretamente profesiones prestigiosas, en las que rol e identidad se presentan estrechamente ligados.

En la perspectiva estructural-funcionalista, la socialización que emerge es aquélla que lleva a asumir plenamente los roles. Sin embargo, para Goffman una teoría de los roles no reductiva o simplista también debe prever la «distancia de rol», es decir, aquella "cuña» que se inserta entre el individuo y su rol, entre «hacer»y «ser» (Goffman, 1961b: 107-108). Ésta nos permite captar la diferencia, mantener la separación entre la obligación del rol (y su definición normativa) y la efectiva ejecución (ibídem: 115).

Emergen de esta forma dos tesis centrales. La primera es que el individuo posee una multiplicidad de sí mismos sociales (o de roles). En un contexto de interacción determinado, está llamado a jugar y a identificarse en un rol particular, dejando al resto en un estado de "latencia». Sin embargo, el individuo no asume el rol situado que encuentra a su disposición hasta el punto de neutralizar el resto de sí mismos sociales. La segunda tesis es que la distancia del rol no es concebida en negativo, sino que, más bien al contrario, desempeña un importante significado funcional: 
1. La distancia de rol es una función comunicativa. Exhibir una distancia significa mostrar a los otros la no asunción total.

2. En segundo lugar, una cierta «desidentificación» del rol se presenta funcional para su ejecución más consciente y eficaz (Goffman, 1961b: 133).

3. La asunción de una distancia de rol es necesaria para gestionar las tensiones que siempre, en cualquier medida, caracterizan a la performance de un actor ante un público.

Sin abrazar el radicalismo liberal de Dahrendorf (1959), Goffman ofrece numerosos fragmentos sobre la presión —incluso psicológica - de los roles, sobre el peso de la "circunspección dramatúrgica», de la disciplina social mediante la que "la fachada de las buenas maneras puede regularse desde dentro" (1959: 69). Por este motivo se apuntaba que la toma de distancia de rol no sólo es un producto normativo, ni tampoco una función comunicativa de conducta de señalación. Y es que en diferentes situaciones, la distancia de rol se puede manifestar bajo formas consideradas como sintomáticas del actor (ibídem: 12-17). Por tanto, la distancia del rol puede asumir un doble y complejo significado. Por una parte, el individuo perfectamente socializado no es el que asume completamente el rol, sino el que es capaz de mirarlo con distancia. Por otra parte, la distancia de rol permanece como el espacio en el que se puede vislumbrar, aunque sólo sea fugazmente, aquel yo «desnudo» que está en el trasfondo de la sociología de Goffman.

\section{Descodificación de la vida cotidiana: ¿variables estructurales o frames?}

Frame Analysis representa un gran intento para afrontar de forma sistemática tanto el problema de la «realidad social», como nuestra experiencia acerca de la realidad. Por este motivo, Goffman recoge, amplia e integra en una nueva construcción, los conceptos de "fachada», representación, escena, entre bastidores, rol y distancia de rol a la luz de un concepto clave tomado de Bateson: el concepto de frame (Goffman, 1974: 11-12).

Frame Analysis puede ser contemplado como un tratado de sociología del conocimiento. Ahora bien, si desde esta perspectiva se presenta como una respuesta al análisis de la «realidad múltiple» de Schütz (1964: 181-232), a través del cual el sociólogo de origen austriaco concibe las "provincias finitas de significado» como formas de «atención» del conocimiento, Goffman sostiene que dichas estructuras no son construcciones mentales (matter of mind), sino que corresponden a la forma de organización de la actividad social (1974: 247).

Frame Analysis emerge como una reelaboración madura de The Presentation of Self(Manning, 1992: 118 y s.), en donde se presenta el proyecto de construir una nueva perspectiva sociológica con la que estudiar la vida social. Si, como ha observado Collins (1988), los primeros escritos de Goffman están marcados por la exigencia de distanciarse de la hegemonía del estructural-funcionalismo, Frame Analysis legítimamente puede ser considerado como el intento de saldar las cuentas con Parsons. Desde este punto de vista, se presenta como la 
respuesta de Goffman a Toward a General Theory of Action (Parsons y Shils, 1951). Las dos tienen cierta semejanza: la ambición del proyecto. Parsons construye una tabla de conceptos, las "variables estructurales», con el fin de "comprender» los diferentes tipos de acciones y roles sociales. Por su parte, Goffman retoma un análisis sistemático de las «definiciones de la situación» que enmarcan tales acciones y relaciones, confiriendo su «significado» social.

En un continuo trabajo de reelaboración e integración de las tipologías de la acción de Weber y de Pareto con la dicotomía toennesiana de Gemeinschaft y Gesellschaft, Parsons había identificado cinco parejas de orientaciones normativas de la acción alternativas entre sí o, como también se explicita, cinco «dilemas de orientación»: universalismo/particularismo, realización/atribución, afectividad/neutralidad afectiva, especificidad/difusividad, orientación al yo/orientación a la colectividad (posteriormente eliminada en obras más tardías). En toda concreta situación social el actor se encontrará con tener que optar consciente o inconscientemente por una de las dos alternativas, y lo hará a la luz de sus motivaciones personales, de la específica situación de interacción, y de los valores y de las normas sociales que dan a una u otra alternativa una mayor «dignidad» moral y social.

Esta ambiciosa construcción, tendencialmente onmicomprensiva, no ha sido muy fecunda, ya que: $a$ ) tiende esencialmente a aludir a contextos estables e institucionalizados, excluyendo muchas acciones que son interesantes e importantes para el análisis sociológico, y $b$ ) en las sociedades contemporáneas, lo que Parsons consideraba orientaciones opuestas o mutuamente excluyentes, en realidad se combinan en los roles más diversos, según relaciones complejas y contingentes que son analizadas situación por situación (Gallino, 1978a, 1978b).

Estas críticas de Gallino al intento de Parsons acerca de la construcción omnicomprensiva, son perfectamente compartidas por Goffman, que ha prestado mucha atención a las "ocasiones» y a los encounters.

Como se ha podido comprobar, para Goffman es la «situación» la que confiere sentido a la acción, situación a la que asigna una mayor centralidad que Parsons y que analiza de forma más refinada y articulada. Una efectiva comprensión de la acción social no puede basarse simplemente en el análisis de normas que, por lo general, guían a la acción en diferentes contextos sociales y simbólicos. Más bien se hace necesario elaborar una teoría sistemática de la relación entre la acción y la situación en la que recaba su significado ésta última. En Frame Analysis Goffman se compromete en este objetivo, aunque no parece conseguirlo del todo.

Diez años antes, Goffman ya había iniciado este trabajo de profundización en su ensayo Fun in Games, publicado en Encounters (1961b), donde aparece por primera vez el concepto de frame. Goffman analiza la situación del juego como ejemplo de todos los «sistemas de actividades». Todas las situaciones sociales se presentan regidas por reglas de relevancia/irrelevancia y por reglas de transformación (ibídem: 15-30). Las reglas de relevancia/irrelevancia contemplan «la realidad» de un sistema situado de actividad. Para ello establecen, 
por una parte, los atributos y caracteres que definen de forma esencial aquella particular situación y, por otra, qué aspectos son contingentes. Tomando el ejemplo de la metáfora del juego, Goffman muestra cómo las reglas de relevancia/irrelevancia estructuran las relaciones sociales normales, y lo hace aludiendo explícitamente a las variables estructurales parsonsianas. La acción racional respecto a un objetivo, con sus rasgos de neutralidad afectiva y universalismo, constituye el principio de acción en las modernas burocracias y el "marco» adecuado de la conducta en los negocios, en la administración y en la justicia, mientras que los sentimientos y las peculiaridades personales de los participantes serán considerados irrelevantes en estos contextos organizativos y, posiblemente, «tenidos bajo control» (ibídem: 18-21).

Todo sistema situado de actividad constituye «un plan de ser, un motor de significados, un mundo en sí, diferenciado del resto de mundos» que asigna a los participantes determinados roles e identidades (ibídem: 23). Aunque estos mundos no sean "creados en el acto", sino que extraen su material intencional del contexto de la más amplia sociedad (donde son relevantes, por ejemplo, el género, la posición social o la profesión de los actores), «todo posible encuentro genera un mundo de significados que sólo pertenece a él» (ibídem: 24). En resumen, Goffman pretende afirmar que las concretas situaciones de interacción gozan de una relativa autonomía respecto a otras situaciones o esferas de actividad, que deriva del particular frame en el que se enmarcan las relaciones.

Existen reglas de transformación relativas a las modalidades en las que los atributos sociales (estatus y roles difusos) de los participantes se hacen valer en un sistema de interacción situada. Si existe una relativa autonomía de los encuentros respecto de su contexto social, también existe una cierta permeabilidad, en el sentido de que el encuentro debe tener en cuenta aquello que los actores espacial y temporalmente manifiestan fuera de la interacción y, por lo tanto, antes de que se produzca. Algunos atributos externos generalmente se expresan (de forma diversa según los actores y las situaciones) en el ámbito de un encuentro.

Goffman insiste en que es muy problemático entender cómo un atributo exterior atraviesa los límites de un encuentro. No existen isomorfismos macromicro, tan sólo «reglas de transformación» mediante las que se seleccionan y se transforman las propiedades originales (estatus, roles, normas, etc.) del mundo exterior.

Frame Analysis sistemáticamente desarrolla la reflexión de Fun in Games: «Mi objetivo - afirma Goffman- es aislar algunos de los framework fundamentales de los que dispone nuestra sociedad, que nos permiten conferir un sentido a los acontecimientos, y analizar la particular vulnerabilidad a la que están sujetos estos frames de referencia» (1974: 15). En su más comprometida obra, Goffman afronta dos desafíos. El primero es prolongar el primitivo esquema de referencia teórico. La asunción del concepto de frame implica una reformulación del concepto de «situación» tal y como había sido concebido en obras precedentes. El segundo desafío es conseguir conciliar dos exigencias 
que a menudo son incompatibles en la sociología contemporánea. Por una parte, Goffman quiere defender un planteamiento de fondo «realista», no lejano del estructural-funcionalista y, sin embargo, netamente contrapuesto al idealismo de las perspectivas constructivistas. Por otra, pretende construir una perspectiva flexible y articulada que dé cuenta de los múltiples niveles de significado a través de los cuales los individuos confieren sentido a su experiencia del mundo social, sin adherirse a las implicaciones extremas de la reflexividad de los etnometodólogos.

Pues bien, para paliar dicha contradicción, Goffman parte de una categoría de frames que define como "primarios» (ibídem: 21-40). Éstos pueden ser naturales o sociales. Luego, si el mundo físico existe fuera de nosotros y tiene una realidad primaria, "cualquier cosa que intente hacer un agente continuamente está condicionada por constricciones naturales», relativas a las características de su cuerpo y del mundo físico (ibídem: 23). Pero también el mundo social es externo al individuo y lo precede, ya que toda sociedad o grupo social elabora para los individuos un conjunto predeterminado de frames primarios. La configuración esencial de toda cultura, cosmología o sistema de creencias —que Goffman define "framework or frameworks»— está constituida por una serie definida de modelos y esquemas interpretativos fundamentales que los individuos asumen como la base relativamente estable de su representación de la realidad (ibídem: 27 y s.; 1981: 108 y s.).

Los frameworks analizan concretamente las imágenes del mundo, las ideas relativas a la naturaleza y a las facultades humanas, las concepciones del cuerpo, el concepto de causalidad y la relación entre acontecimientos, etc. Estos esquemas fundan el común "sentido de la realidad», aquel orden cognitivo y moral — como dicen Durkheim y Parsons - que garantiza la fundamental integración de la sociedad. Goffman insiste en el carácter de realidad y objetividad de los frames primarios, que existen antes de las situaciones concretas en que los individuos se comprometen. A diferencia de la perspectiva mental de las «realidades múltiples» schutziana, para Goffman las convenciones de framing con las que dotamos de sentido a los acontecimientos y a nuestro mismo obrar son datos colectivos, aunque estén en la conciencia de todo miembro de la sociedad (Helle, 1995: 227).

Sobre la base relativamente estable y dada por descontada del «enmarque» primario de la realidad, los individuos posteriormente construyen los niveles de significación uno sobre otro, de modo progresivo añadiendo complejidad y artificialidad. Goffman entonces reconduce los mismos a dos formas principales: la transformación «en clave» (keying) y la manipulación (fabrication) (1974: 40-82)

Goffman identifica diferentes tipos de keying: las ficciones; las competiciones; las ceremonias; las pruebas y las ejecuciones técnicas en ambientes controlables particularmente importantes con la finalidad del adiestramiento o del aprendizaje; la redefinición más o menos temporal de estatus y roles sociales. A su vez, las transformaciones en clave puede ser retransformadas (re-keyed) dentro de nuevos marcos. 
A pesar de que la creciente complejidad de los procesos de framing puede producir fenómenos de perverso enmarque o de perversa interpretación (Dua, 1990) «los individuos también pueden producir intencionalmente una confusión de frames con los que interactúan" (1974: 7, 83-123). De este modo y al igual que las transformaciones en clave, las fabrications se basan en un marco primario dotado de sentido. Sin embargo, mientras que en las acciones de keying todos los actores interpretan la situación del mismo modo, en las manipulaciones, algunos actores crean "falsos marcos» para engañar a los otros sobre lo que realmente está sucediendo. Sin embargo, la más importante distinción entre ambos conceptos se refiere a las diferentes finalidades de las manipulaciones.

Entre las estrategias de manipulación que persiguen la ventaja del productor conviene recordar ciertos artificios o engaños legales, la falsa publicidad y el hacer trampas en el juego (ibídem: 87-109). Por otra parte, Goffman sugiere distinguir entre aquellas situaciones en las que los individuos se enredan en las fabrications de las que son artífices.

Goffman desarrolla un amplio análisis de las «actividades exteriores a los marcos», es decir, todas aquellas acciones en las que, de modo más o menos intencional o visible, los individuos ponen en marcha una línea de actividad divergente respecto del frame principal (ibídem: 201-246).

Las transformaciones en clave, las maquinaciones y las actividades exteriores a los marcos representan una amenaza para nuestra confianza en el frame primario, lo que provoca cierta inseguridad respecto al estatuto de la realidad de cuanto sucede entorno a nosotros. Sin embargo, Goffman observa que existen mecanismos que alimentan nuestra confianza en el frame, dispositivos de anclaje que nos amarran a lo que nos parece real (1974: 247-300). Estos mecanismos son: a) la utilización de paréntesis que circunscriben una actividad en el espacio y en el tiempo, distinguiéndola de la actividad colindante; $b$ ) la estabilidad del sistema de roles sociales (ligada a la asunción del rol por parte de los individuos) que garantiza la indispensable previsión de las acciones sociales; c) la posibilidad de que los acontecimientos dejen trazos permanentes en el tiempo, una memoria en forma de "documento", que permita verificar qué ha sucedido efectivamente en el pasado; d) la capacidad de identificar los elementos estructurales de un frame, y e) la presuposición, relativa a la naturaleza humana, según la cual los actos de un individuo son, en cualquier medida, la expresión de un "yo estable» (perduring self) que permanece más allá de los roles que interpreta en un determinado momento (Manning, 1992: 126-129).

En conclusión, Goffman considera algunos frames más fundamentales que otros y a ellos confiamos nuestro sentido de la realidad. Las transformaciones en clave siempre conservan una relación con la realidad primaria.

\section{Acción social y lenguaje cotidiano}

Abordar la teoría de la acción social en Goffman implica prestar una especial atención a su última obra: Forms of Talk (1981). En ella, Goffman retoma y 
refina las categorías de análisis de la interacción elaboradas en obras precedentes.

El estudio de la relación entre lenguaje y acción ya había sido tratado por Austin en su teoría de los actos lingüísticos (1962) y por Searle (1969), y más recientemente está presente en los análisis de la conversación y del discurso (Van Dijk, 1985; Galimberti, 1992). Goffman está muy interesado en estos estudios, aunque se da cuenta de sus límites desde el punto de vista sociológico. La idea fundamental de Goffman es que toda práctica discursiva siempre está «enmarcada» en un contexto interactivo. Los actos lingüísticos sólo pueden comprenderse si son considerados como «flujos» sociales.

A la luz de esta perspectiva, Goffman pretende reformular las nociones de «hablador» y «escuchador». Éstas son inadecuadas por su carácter unidimensional. Junto a los aspectos verbales, siempre existe una dimensión no verbal que funciona como "canal complementario» de la comunicación, permitiendo la recepción mediante señales visibles de la dirección de la mirada, de las expresiones faciales, de la postura, etc. (1981: 181-184). En segundo lugar, los roles del hablador y del escuchador pueden descomponerse en términos analíticos. En la acción del hablador, se pueden reconocer tres roles diferentes: el animador, el autor y el mandante (ibídem: 199-203; 242-248). El escuchador (o receptor), a su vez, puede ser receptor destinatario de la comunicación o un asistente. Posteriormente, existen acciones secundarias, trasversales o laterales, que recortan de forma diversa el espacio comunicativo entre participantes y asistentes (ibídem: 184-191).

La definición de los actos comunicativos como «flujos» sociales tiene una segunda consecuencia: la conversación - como cualquier otro tipo de discurso- siempre es, en su estructura, un «intercambio ritual» (ibídem: 46). Y, como tal, presenta todas las dinámicas, los vínculos y las constricciones que Goffman analiza en obras precedentes, en las que nos detenemos a continuación:

1. Los «flujos» realizados por los participantes «tienen una función de gestión del sí mismo» (ibídem: 190).

2. Todos los participantes están comprometidos en «salvar la situación».

3. En toda situación comunicativa el estatus de los habladores depende de la específica «estructura participativa», esto es, se trata de un consenso de relaciones formales o informales, espontáneas o rígidamente programadas, simétricas o asimétricas, paritarias o jerárquicas, serias o menos serias (Goffman, 1981: 27-28).

4. La dimensión ritual de la comunicación y las características específicas que ésta asume depende de los diferentes contextos culturales y, en consecuencia, pueden cambiar mucho de una sociedad a otra (ibídem: 46).

5. Continuando con la línea argumental de Frame Analysis, Goffman observa que el acto de hablar en una situación interactiva cara a cara se encuentra sometido a continuos procesos de "cambio del código", a cambios de frame (o, como aquí señala, de footing) (ibídem: 177, 180). 
Concluyendo, Goffman se distancia de todos aquellos planteamientos lingüísticos y microsociológicos para los que la comunicación no es una dimensión o una consecuencia de la acción, sino que más bien se constituye como la fuerza productiva. Coherente con su perspectiva "realista», sin embargo considera que es necesario partir de la estructura de la acción social para comprender la estructura de la comunicación.

\section{Orden de la interacción y orden social}

Para la tradición sociológica que va desde Durkheim hasta Parsons, la misma existencia de la sociedad depende de la interiorización por parte de los individuos de los valores y las normas que fluyen desde las instituciones centrales de la sociedad. Sin embargo, para Goffman, el orden social se genera localmente mediante las reglas ceremoniales y los rituales que gobiernan las relaciones cara a cara: el orden de la interacción está en la base del orden social (Strong, 1988; Burns, 1992).

En segundo lugar, Goffman habla explícitamente de un sistema de obligaciones y expectativas en términos morales (1956: 476 y s.). Cuando los actores someten su comportamiento al orden ceremonial dominante, ofreciendo su contribución al flujo ordenado de los mensajes, su objetivo es «salvar la cara, el efecto es salvar la situación» (1955: 224). Sin embargo, cuando el orden expresivo es violado «encontramos que dos individuos corren el riesgo de ser desacreditados» (ibídem: 228). A la petición moral del actor de ser considerado por la imagen de sí que proyecta en la interacción, corresponde la solicitud del público de poder contar con «apariencias normales» de la imagen proyectada (1959: 23; 1971: 158).

Si Goffman se ubica en la tradición de Durkheim en cuanto que se adhiere a la idea de que la relación social es, en su esencia, una realidad moral (Collins, 1988), las categorías con las que define la conducta social - moralmente «correcta»— no son las típicas de dicha tradición. Nos referimos a los binomios: normal-anormal, conforme-desviado, funcional-disfuncional (MacCannell, 1990). Por el contrario, Goffman mantiene que la "correcta" performance no depende primariamente de los movimientos psicológicos y de la sinceridad del actor, sino de que el mismo esté socialmente autorizado para asumir un cierto personaje o rol y lo haga con el necesario «cuidado» y coherencia expresiva.

Para el filón normativo de la acción que va desde Durkheim hasta Parsons, la interiorización de los valores y de las normas sociales por parte de los individuos necesariamente asume el carácter de la sinceridad. Sin embargo, desde su primera obra, Goffman aclara que para los fines del mantenimiento del orden interactivo ( $y$, más en general, social) no es necesario que todo individuo «exprese cándidamente aquello que en realidad siente, y apruebe sinceramente los sentimientos expresivos de los presentes» (Goffman, 1959: 20). Es suficiente que «todo participante reprima sus sentimientos inmediatos, ofreciendo una interpretación de la situación que considere al menos momentáneamente aceptable por los otros» (ibídem). De esta forma, no sorprende la aparente paradoja de 
la moralidad del obrar: «En sus ropajes de actores, los individuos tienen interés en mantener la impresión de que están viviendo a la altura de los muchos standard según los cuales ellos y sus productos vendrán juzgados. Así como estos standard son numerosos y omnicomprensivos, los individuos-actores viven más de cuanto podamos creer de una forma moral. Pero en cuanto actores, los individuos no están interesados tanto en el problema moral de realizar estos standard, cuanto en lo a-moral de construir una impresión convincente del hecho de que sean alcanzados. Nuestra actividad tiene que ver especialmente con cuestiones morales, pero, en cuanto actores, no la consideramos en sus consecuencias morales: como actores somos traficantes de moralidad» (1959: 287). Para Goffman, la principal connotación «moral» de la performance consiste en su previsión o confianza. Las microrreglas ceremoniales tienen el objetivo de conectar obligaciones y expectativas para permitir la necesaria previsión de la acción del otro.

La copresencia física siempre comporta oportunidades y riesgos (1983: 6). En el ensayo sobre el riesgo (Where the Action Is), Goffman observa que «el sujeto siempre está en peligro, ya sea por la posibilidad de ligámenes accidentales entre los acontecimientos, ya sea por la vulnerabilidad de su cuerpo, ya sea por el hecho de que en las situaciones sociales es necesario mantener apariencias correctas» (1967: 193). De esta forma, se hace necesario, para el «normal» desarrollo de las relaciones sociales, el control del riesgo mediante técnicas inmanentes a las mismas situaciones interactivas, que incluso serán similares en sociedades diferentes (1983: 8). Tales técnicas consisten esencialmente en la rutina y la ritualización de la acción. En síntesis: Goffman se adhiere al filón normativo de la teoría de la acción, pero desde una posición particular. El sociólogo norteamericano no cree que, en una sociedad muy diferenciada, el orden social pueda basarse única o principalmente en un consenso sustancial referido a valores generales y abstractos. Además, se hace necesario un "consenso operativo». Sin embargo, estas normas no prescinden del todo de los valores. Se fundan en la confianza de que los individuos se anticipan recíprocamente dando crédito a las definiciones del sí mismo y de la situación proyectada por los otros (es decir, a la petición moral que avanzan) y, al final, sobre el valor fundamental de la sacralidad del individuo (1956: 486, 499). Ahora bien, para Goffman estos valores constituyen los valores implícitos constitutivos de la misma práctica interactiva cotidiana (1955; 1956; 1959: 11-28; 1971: 157-216).

\section{El actor: la fisonomía del «enlace»}

Toda la perspectiva sociológica goffmaniana se basa en una instalación dualista, al ser sus principales categorías "parejas» de categorías: actor-público, escena-entre bastidores, rol-distancia de rol, frames primarios-transformaciones $y$, naturalmente, actor-personaje (MacCannell, 1990). Esta estructura dualista de fondo ha llevado a diferentes estudiosos a considerar la teoría de Goffman como una teoría de los «dos yo». Por debajo del «yo social» representado como resultado de las expectativas sociales, se escondería el verdadero yo, dotado de una identidad originaria. 
Algunos lo conciben como un «yo prisionero» de las convenciones sociales y de los roles representados; otros como un "yo utilitarista", manipulador cínico de fachadas en beneficio propio. Otra línea interpretativa, alentada por numerosas expresiones del mismo Goffman, sostiene una tesis diferente: el individuo goffmaniano está constituido por una multiplicidad de selves que se alternan ante públicos diferentes, entrando en conflicto entre sí, limitándose recíprocamente, sin que se pueda captar un estrato de la personalidad más fundamental, que sustente todos los aspectos y las modelaciones de sí mismo (Manning, 1992). La diversidad de interpretaciones se debe a que Goffman jamás consigue aclarar del todo la ambigüedad de la naturaleza del sí mismo. Del contexto de su obra resulta que tal concepto no implica al individuo en cuanto tal, considerado en la totalidad de sus expresiones y determinaciones, sino el sí mismo ubicado, es decir, el self que se muestra en una particular situación social (1959: 288). En segundo lugar, Goffman observa que el sí mismo como personaje es una imagen idealizada (ibídem). En fin, estos caracteres del personaje no son ligados por Goffman a la especificidad del individuo, sino a las características del contexto en que actúa (ibídem: 288-289). Por tanto, el sí mismo parcial o virtual se presenta como el producto de una escena que es representada y no como su causa, es un «efecto dramatúrgico» (ibídem: 289).

Sin embargo, en las relaciones sociales generalmente la parte es considerada el todo. En efecto, el sí mismo como personaje es aquello que concretamente se muestra en las situaciones de interacción, aquello que el resto de participantes pueden y deben tener en cuenta. Y, según Goffman, también es la única dimensión del sujeto-actor accesible a la observación del sociólogo. De esta forma, éste concentra su atención en el personaje y en las técnicas dramatúrgicas con las que ilumina los diversos contextos de interacción (Giglioli, 1990), mientras el actor permanece en la sombra. En realidad, no es que falten las referencias al actor, sino que éstas son ocasionales y, casi siempre, entre líneas. Goffman declara que los atributos fundamentales del individuo son «de naturaleza psicobiológica» $\mathrm{y}$ "no son simplemente la impronta pictórica de representaciones particulares» (1959: 290). Sin embargo, el actor es definido en negativo, al aludir al personaje y al estar en función del personaje.

En la introducción de Interaction Ritual (1967: 5), Goffman señala que el objeto de su análisis no es el individuo y su psicología, sino «las relaciones sintácticas existentes entre los actos de personas que se encuentran directamente en contacto". Y, sin embargo, Goffman reconoce que su análisis "obviamente presupone una psicología, pero que debe ser limitada y simplificada para que pueda adaptarse al estudio sociológico de la conversación» (ibídem: 6).

El actor tiene «capacidad de aprender, y esta capacidad es ejercitada para prepararse una parte» del guión (1959: 290). Sin embargo, la adquisición de la necesaria "competencia» dramatúrgica jamás le alivia completamente de la tensión del «fatigado fabricante de impresiones, inmerso en el objetivo humano de poner en escena una representación» (ibídem: 288). Posteriormente, Goffman también hace un fugaz guiño a las necesidades y a los movimien- 
tos psicológicos: el actor «está preparado para tener fantasías y sueños [...] hasta el punto de que la representación está desacreditada para su puesta en escena» (ibídem, 290).

Como otros muchos sociólogos contemporáneos, Goffman escoge mantener al sujeto en los márgenes del horizonte epistemológico de la (su) sociología. La (su) sociología no capta al sujeto en sí, sino sólo y siempre en las formas y bajo las semblanzas de tantos selves ubicados y parciales que representa, y que los otros esperan que represente. La elección de tener al sujeto fuera del discurso sociológico no es, obviamente, neutral. Se fundamenta en presuposiciones explícitas o implícitas sobre la naturaleza humana, y sobre como ésta se realiza y se actualiza en la vida social. Toda elección metodológica tiene implicaciones ontológicas.

¿Y Goffman? Algunos pasajes autorizan el juicio de que habría realizado una verdadera y propia "disolución del sujeto» (Giglioli, 1984b; Crespi, 1985, 1989; MacCannel, 1990). Sin embargo, si tenemos en cuenta todo el contexto de su obra, debemos reconocer que las necesidades y las capacidades atribuidas al actor, aunque descritas de forma sumaria, son muy relevantes. A diferencia del modelo demasiado «mecanicista» del actor parsonsiano o de la delgada figura del member de la etnometodología, el actor de Goffman aparece como capaz de interpretar con habilidad personajes comprometidos y fatigosos; de sumergirse en ellos y de distanciarse; de conjugar la exigencia de "salvar» la propia fachada conjuntamente con «salvar» la situación; de cooperar activamente con los otros, pero también de «jugar a» cooperar o de ordenar manipulaciones en su contra, es decir, se refiere a un sujeto consciente "protagonista» de su propia existencia. No obstante la consciente reducción antipsicológica, provoca que «exista en el individuo goffmaniano la constante voluntad de salvar el propio sí mismo, la propia identidad y coherencia, la propia imagen, que no puede explicarse sin aludir a las categorías de tipo existencial» (Crespi, 1985: 267; 1989: 85-86).

Pero hay también otro aspecto que es necesario considerar: el sentido de la dialéctica latente y no resuelta entre el actor y los «yo sociales» representados. Tal dialéctica traslada a dos autores que han influenciado la génesis del pensamiento sociológico de Goffman: Freud y Durkheim. Más allá de la simple caracterización dualista del sujeto, lo que aproxima a Goffman con Freud y Durkheim - y sin embargo lo aleja de la visión "reconciliadora» de Mead y Parsons - es la idea de esta tensión no reducible entre el «enlace» y los selves sociales que una y otra vez están insertados. Esta tensión no se manifiesta, sin embargo, en el riesgo de disolución anómica del sujeto o en el nerviosismo inducido por el imperfecto control del pulso instintivo, sino sólo en los "pequeños espasmos desnudos del sí mismo» (1967: 307).

En conclusión, Goffman considera que para comprender la acción social es mejor «empezar por lo exterior al individuo para, posteriormente, trabajar en lo interior, y no al contrario" (1959: 124). Su análisis de la acción social se centra en cuatro elementos principalmente: el comportamiento del actor social en la escena, la forma en que se presenta en-cuanto-personaje, el papel que 
muestra seguir y el contexto interactivo en el que su performance se ubica (Mora, 1997). En este sentido, es compartida la observación de que su teoría de la acción no pone el énfasis en el concepto de actor como entidad autónoma y creativa, tal y como sucede en la mayor parte de las teorías microsociológicas (Giglioli, 1990: 14 y s.). Es más, la tesis que hemos sostenido es que, aún evitando afrontar de forma explícita el problema de la naturaleza del sujeto de la acción, Goffman diseña los trazos de un «modelo mínimo de actor» que, por otra parte, revela el comportamiento de un personaje, dotado de necesidades, actitudes y capacidades que le permite asumir las complejas y fatigosas rutinas representativas y sociales cotidianas.

\section{Bibliografía}

AleXander, J. (1983). The Modern Reconstruction of Classical Thought: Talcott Parsons, Berkeley-Los Angeles: The University of California Press.

- (1987). «Simbolic Interactionism: Individualism and the Work of Blumer and Goffman». En AleXANDer, J. Twenty Lectures, Sociological Theory since World War II. Nueva York: Columbia University Press, 215-237.

Austin, J. (1962). How To Do with Words. Londres: Oxford University Press.

Bateson, G. (1955). «Ecology of Mind». En A.P.A. Psychyatric Research Report, 2. Bovone, L.; Rovati, G. (comp.) (1992). L'ordine dell'interazione. La sociologia di Erving Goffman. Milán: Vita e Pensiero.

BuRns, T. (1992). Erving Goffman. Londres: Routledge.

COLLINS, R. (1984). «Riflessioni sul passaggio delle generazioni intelettuali». Rassegna italiana di sociología, XXV, n. 3: 351-369.

- (1988). «Theoretical Continuities in Goffman's Work». En Drew, P.; WoOtTon, A. (eds.): 41-63.

CRESPI, F. (1985). Le vie della sociologia. Bolonia: Il Mulino.

- (1989). Azione sociale e potere. Bolonia: Il Mulino.

Dahrendorf, R. (1959). Homo sociologicus, Westdeutscher Verlag, Köln-Opladen.

DANZiger, K. (1976). Interpersonal Communication. Pergamon Press.

Dawe, J. (1973). «The Underworld-view of Erving Goffman». British Journal of Sociology, 24: 246-253.

De BIASI, R. (1995). «Cornici». Aut Aut, n. 269: 5-15.

Drew, P.; WoOtTON, A. (eds.) (1988). Erving Goffman. Exploring the Interaction Order. Cambridge: Polity Press.

DuA, H. (1990). «The Phenomenology od Miscommunication». En RigGins, S. (ed.).

DurKheim, E. (1964). La reglas del método sociológico. Buenos Aires: Dédalo.

- (1968). Las formas elementales de la vida religiosa. Buenos Aires: Schapire.

GalimberTi, C. (comp.) (1992). La conversazione. Milán: Guerini.

Gallino, L. (1978a). Voz «Azione sociale». En Gallino, L. Dizionario di sociologia. Turín: Utet, 69-73.

- (1978b). Voz «Variabili strutturali». En Gallino, L. Dizionario di sociologia. Turín: Utet, 741-743.

Giddens, A. (1988). "Goffman as a Systematic Social Theorist». En Drew, P; WoOtTon, A. (eds.): 250-293.

Giglioli, P.P. (comp.) (1984a). Linguaggio e società. Bolonia: Il Mulino.

- (1984b). «Una occasione mancata». Rassegna Italiana di Sociología, 25: 144-151. 
- (1990). Rituale, interazione, vita quotidiana. Saggi su Goffman e Garfinkel. Bolonia: Clueb.

Giglioli, P.P; Dal Lago, A. (comp.) (1983). Etnometodologia. Bolonia: Il Mulino. Giglioli, P.P.; Cavicchioli, S.; Fele, G. (1997). Rituali di degradazione. Bolonia: Il Mulino.

Goffman, E. (1955). "On Face-Work: An Analysis of Ritual Elements in Social Interaction». Psychiatry, 18, n. 3: 213-31.

- (1956). «The Nature of Deference and Demeanor». American Anthropologist, 58: 473-502.

- (1959). The Presentation of Self in Everyday Life. Nueva York: Doubleday Anchor Books.

- (1961). Asylums. Nueva York: Doubleday Anchor Books.

- (1961). Encounters: Two studies in the Sociology of Interaction. Indianapolis: BobbsMerril; contiene los artículos «Fun In Games» y «Role Distance».

- (1963). Behavior in Public Places. Notes on the Social Organization of Gatherings. Glencoe: Macmillan.

- (1964). «The Neglected Situation». American Anthropologist, 66, n. 6. Parte II: 133-136.

- (1967). Interaction Ritual. Nueva York: Doubleday Anchor Books.

- (1969). Strategic Interaction. University of Pennsylvania Press, Filadelfia.

- (1971). Relations in Public. Nueva York: Basic Books.

- (1974). Frame Analysis. Nueva York: Harper \& Row.

- (1981). Forms of Talk. Filadelfia: University of Pennsylvania Press.

- (1983). «Interaction Order». American Sociological Review, 48: 1-17.

- (1993). «An Interview with Erving Goffman» (Verhoeven, J.). Research on Language and Social Interaction, 26, 3: 317-348.

Habermas, J. (1981). Theorie des Kommunikativen Handelns. Frankfurt a. M.: Suhrkamp Verlag.

Helle, H. (1995). «Erving Goffman: un interazionista simbolico?». En GUBERT, R.E.; TOMASI, L. (comp.). Teoria sociologica ed investigazione empirica. Milán: Angeli. KendON, A. (1998). «Goffman's Approach to Face-to-Face Interaction». En Drew, P.; WOOTTON, A. (eds.): 14-40.

Knorr-Cetina, K. (1981). «The Micro-sociological Challenge of Macro-sociology: Towards a Reconstruction of Social Theory and Methodology». En KNORR-CETINA, K.; CiCOUREL, A. (eds.). Advances in Social Theory and Methodology: Towards an Integration of Micro- and Macro-sociologies. Boston-Londres: Routledge \& Kegan Paul.

LAMO DE EsPinOSA, E. (2001). "La sociología del siglo XX». Revista Española de Investigaciones Sociológicas, n. 96: 21-49.

Linton, R. (1936). The Study of Man. Nueva York: Appleton-Century-Crofts.

MacCannell, D. (1990). «The Descent of the Ego». En Riggins, S. (ed.): 19-40. MANnING, P. (1989). «Ritual Talk». Sociology, 23, n.3: 365-385.

- (1992). Erving Goffman and Modern Sociology. Cambridge: Polity Press.

Merton, R. (1968). Social Theory and Social Action. Nueva York: The Free Press.

MORA, E. (1992). «Lavoro di faccia: il contributo di Goffman all'approccio comunicativo della teoria sociale». En BovONE, L.; RovATI, G. (comp.).

- (1997). Voz «Attore sociale». En Sociologia, Enciclopedia tematica aperta. Milán: Jaca Book.

Parsons, T. (1951). The Social System. Glencoe: Free Press.

- (1969). Politics and Social Structure. Nueva York: The Free Press. 
- (1971). The System of Modern Societies. Englewood Cliffs: Prentice-Hall.

- (1977). Social System and the Evolution of Action Theory. Nueva York: The Free Press.

PARSOnS, T.; SHILS, E. (eds.) (1951). Toward a General Theory of Action. Cambridge, Mass.: Harvard University Press.

Riggins, S. (ed.) (1990). Beyond Goffman: Studies in Communication, Institution and Social Interaction. Nueva York/Berlín: Mouton de Gruyter.

SchÜTZ, A. (1964). «On Multiple Realities». En Collected Papers I. The Problem of Social Reality. Nijhoff, Den Haag.

SeArLe, J.R. (1969). Speech Acts. Londres: Cambridge University Press.

Strong, P.M. (1988). «Minor Courtesies and Macro Structures». En Drew, P.; WotTON, A. (eds.): 228-249.

TÖNNIES, F. (1947). Comunidad y sociedad. Buenos Aires: Losada.

VAn DijK, T. (1985). Handbook of Discourse Analysis. Londres: Academic Press.

Weber, M. (1983). Economía y Sociedad. México: FCE.

- (2001). Ensayos sobre metodología sociológica. Buenos Aires: Amorrortu. 